Egyptian Journal of Aquatic Biology \& Fisheries

Zoology Department, Faculty of Science,

Ain Shams University, Cairo, Egypt.

ISSN $1110-6131$

Vol. 24(2): $47-68$ (2020)

www.ejabf.journals.ekb.eg

\title{
On some Nereididae (Polychaeta) with new records for the Egyptian waters
}

Faiza A. Abdelnaby

National Institute of Oceanography and Fisheries Alexandria, Egypt

Faiza_abdelnaby@yahoo.com

\begin{abstract}
ARTICLE INFO

Article History:

Received: Dec. 19, 2019

Accepted: March 21, 2020

Online: April 2020

Keywords:

Polychaeta

Nereididae

Suez Canal

Suez Gulf

Red Sea

Mediterranean coast

In the present study 18 Nereididae species have been recorded, belonging to 8 genera, in fouling samples taken during 2015 from Suez Canal, and during 2010 from Hurghada (Red Sea), and in sediment samples collected from the Suez Gulf in 2018, from Port Said, Rashid, from Damietta and Marina in 2013, and from El Dabaa in 2017. Nine of the collected species were previously recorded as alien, by contrast, 6 are considered newly recorded species for Egyptian waters: Pseudonereis variegata and Nereis jacksoni are viewed as new to the Suez Canal and the Suez Gulf. Ceratonereis (Composetia) hircinicola and Leonnates decipiens are recorded from the Suez Gulf and the Egyptian Mediterranean coast, so they are considered exotic organisms introduced to the Mediterranean by ship or ballast water. Also, Ceratonereis mirabilis and Leonnates indicus are considered a new records for Egyptian Mediterranean waters. Notes of description included, likewise photographs of each species. This study is another endeavor to add new records of Nereididae species in the Egyptian waters, recorded for the first time, which enriches our knowledge of this family and is considered an addition to the list of polychaetes in Egypt.
\end{abstract}

\section{INTRODUCTION}

Nereididae species are generally found in marine and some freshwater communities, living from intertidal zone to abyssal depth. They live in mucous tubes to form a temporary living space and most of them are considered carnivores; additionally some are herbivorous or deposit feeders feeding on algae, microscopic organisms and detritus (Fauchald and Jumars, 1979). Only one species is reported as filter feeder (Esselink and Zwarts, 1989).

The family has an enormous number of genera and species (Hilbig, 1997). Wehe and Fiege (2002) identified 71 species from the Seas around the Arabian Peninsula. Hartman (1974) listed 16 genera and 103 species from the Red Sea and the Malay Archipelago of 
the Indian Ocean. Likewise, Rosenfeldt (1989) reported 37 species of this family inside the list of the Expeditions Meseda (1977) and Meseda II (1979) from the deep-water in the Red Sea. Amoureux et. al. (1978) studied polychaetes in the Suez Gulf and the Aqaba Gulf, recorded 17 Nereididae species of which, 13 species were reported during Fauvel's survey of the Suez Canal (1927). Ben Eliahu (1972, 1991) studied Nereidedae polychaetes obtained from the Suez Canal. Likewise Abd Elnaby (2009) and Selim (2009) distinguished polychaetes gathered from the Suez Canal. Barbary (1992) investigated the polychaete fauna in Lake Temsah and detailed some Nereididae species. In addition, Nereididae species were concentrated before from the Mediterranean coast of Egypt, just from Alexandria shores.

The present study is a contribution to the knowledge on the Egyptian Nereididae species, providing morphological information, and distribution including photos of growing species.

\section{MATERIAL AND METHODS}

Samples of bottom fauna were collected during 2017 and 2018 from Suez Gulf. Fouling samples were collected from the Suez Canal in 2015. The Red Sea hard bottom samples were collected from Hurghada in 2010. Additional samples were collected from the western Mediterranean coast of Egypt (Marina and El Dabaa, 2017), and from the eastern Mediterranean shoreline of Egypt (Port Said, Abo-Qir, Damietta, Rashid, and El Burrullus 2013) (Fig. 1). A Van Veen grab $(25 \times 25 \mathrm{~cm})$ was used to collect sediment samples. Metal blade was utilized to curves rocks for fouling samples. In the laboratory samples were washed through $0.1 \mathrm{~mm}$ mesh sieve for small polychaetes and $0.5 \mathrm{~mm}$ for the remainder of fauna, and afterward fixed with a 70\% ethyl alcohol solution, materials were selected under a stereomicroscope, at that point species distinguished to species level. The photographs of some species were taken by a digital camera attached to stereo and compound microscopes.

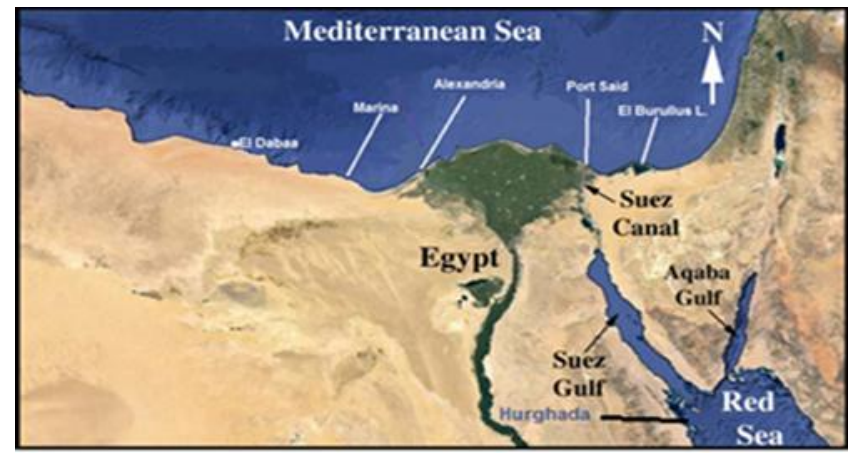

Figure (1) A map of northern Egypt showing sampling stations. 


\section{RESULTS}

Complessively 18 Nereididae species, belonging to 8 genera have been recorded, 6 of which are new records for Egyptian waters: Among the collected taxa, 9 are confirmed as alien species (Table 1).

Table (1) Distribution of Nereididae species recorded in the present study. Alien* species recorded before, N.R (new recorded for Egyptian waters).

\begin{tabular}{lllllll}
\hline Species & Suez & Suez & Red & South Med. \\
& Gulf & Canal & Sea & Africa & for & Egypt \\
& & & & & \\
\hline Platynereis dumerilii (Audouin\& & - & + & + & + & & Recorded before
\end{tabular}

Milne Edwards, 1833)

Platynereis australis Schmarda, $1861+$

Platynereis insolita Gravier, 1901

Platynereis calodonta Kinberg, 1865

Platynereis nadiae Abbiati \& Castelli, 1992

Neanthes kerguelensis (McIntosh,

$\begin{array}{llllll}- & - & - & - & + & \text { N.R. from Marina } \\ - & + & + & + & - & \text { Recorded before* } \\ - & + & + & + & + & \text { Recorded before * } \\ - & - & + & + & + & \text { R. before from R. Sea* } \\ + & + & + & + & + & \text { Recorded before* } \\ + & + & + & + & + & \text { Recorded before* } \\ - & - & + & - & - & \text { N.R. S.G\& E. Med. } \\ & & & & & \text { coast of Egypt } \\ - & + & + & + & + & \text { Recorded before * } \\ - & - & + & + & - & \text { N. Recorded } \\ - & + & + & + & + & \text { Recorded before * } \\ - & + & + & - & - & \text { Recorded before } \\ - & + & - & - & - & \text { N. Recorded } \\ - & + & + & + & + & \text { Recorded before } *\end{array}$
1885)

Neanthes willeyi (Day, 1934)

Alitta succinea (Leuckart, 1847)

Nereis jacksoni Kinberg, 1865

Nereis persica Fauvel 1911

Ceratonereis mirabilis Kinberg, 1865. +

Ceratonereis (Composetia) hircinicola -

(Eisig, 1870)

Leonnates decipiens Fauvel, 1929

$+\quad+\quad-\quad$ Recorded before

$+\quad+\quad-\quad$ Recorded before

$+\quad+$

N.R. from Hurghada

N.R. from Hurghada*

Leonnates indicus Kinberg, 1865

Perinereis cultrifera (Grube, 1840)

Perinereis heterodonta (Gravier 1899) -

Pseudonereis variegata (Grube, 1857) -

Pseudonereis anomala (Gravier 1899) - 


\section{Family Nereididae Savigny, 1822.}

\section{Genus: Platynereis Kinberg 1865}

\section{Platynereis dumerilii (Audouin \& Milne Edwards, 1833) (Fig. 2 A-E)}

Day 1967: 306 fig 14.4. d-k; Fischer and Dorresteijn, 2004: 314 fig. 1, 2; Dean, 2001: 61, figs. 58-62.

Notes: Thirty six specimens were collected from Egyptian Mediterranean coast (2013). Body 18- 34 mm long, with 65-92 segments (Fig. 2 A, B). Proboscis provided with small conical paragnaths arranged as follow: G.I and $\mathrm{II}=$ missin, G.III= two transverse rows of pectinate paragnaths, $G . V=$ three rows of small conical Paragnaths, $G . V=$ missing, $G . V=$ two rows of small paragnaths, G.VII and VIII= two rows of very small paragnathsarranged in small patches. Notopodial glands are present (Fig. 2 D. Two conical notopodial lobes present and a longer dorsal cirrus posteriorly (Fig. 2 E). Notochaetae spinigers, from the middle parapodia there are two to three homogomph falcigers. Blades of falcigers with a distal terminal knob, elongated and bent back (Fig. 2 C). Neuropodia with spinigers and falcigers. This species was found within Fouling collection from Rashid and Damietta Eastern Mediterranean coast of Egypt (2013). It previously recorded from Alexandria by Abd Elnaby (2005).

Type Locality: La Rochelle (France, NE Atlantic).

Distribution: Platynereis dumerilii, initially reported from the Mediterranean, has at present a wide geographical distribution in warm waters, from the coasts of North Africa to the Irish Sea (Hartmann-Schroeder, 1996), and from South West Africa around the Cape (Day, 1967), so that, Hartmann-Schroeder (1996), considered it " a cosmopolitan form.

\section{Platynereis australis (Schmarda, 1861) (Fig. 3 A-B)}

Day, 1967: 305, fig.14.4m; Imajima, 1972: 82-85, figs 2Ia-o, 22.

Notes: One specimen collected from Hurghada 2010. Length of body up to $25 \mathrm{~mm}$, with 55 segments. Characters of this species are similar to those of $P$. dumerilii except for notopodial falcigers absent and also for longer dorsal cirri and notopodial lobes of posterior parapodia. It collected from Hurghada 2010.

Type locality: Auckland, New Zealand.

Remarks: This species was already reported from Red Sea by Day (1967).

Distribution: Australia (Eastern Australia, Western Australia. New Zealand. South West Africa, Cape. Red Sea, Ceylon, Madras, Andaman Is (Day, 1967). 


\section{Platynereis insolita Gravier, 1899 (Fig. 4 A-B)}

Day, 1967: 307 fig. 14.4.1; Ganesan and Monisha, 2017.

Notes: One specimen was collected from Red Sea (Hurghada, 2010), 12mm in length, 30 segments. This species is great similar to $P$. dumerilii but differs in the shape of notopodial homogomph falcigers, having the tip of the blade smoothly curved. This species was collected from Hurghada 2010.

Type locality: Red Sea.

Remarks: This species was described from the Red Sea by and also reported after by Day (1967).

Distribution: Red Sea- Gulf of Suez; Gulf of Aden Tadjoura; Indian Ocean - Ceylon, Madras (Day, 1967; Wehe and Fiege, 2002).

\section{Platynereis calodonta Kinberg, 1865 (Fig.5 A-E)}

Day, 1967: 36 fig. 14.4.a-c.

Nereis (Platynereis) hewitti Day, 1934:44, fig. 9 a-f.

Notes: Two specimens. Body about 20, 25mm, with up to 35 segments. Proboscis with comb-like paragnaths, more strongly marked than other Platynereis species, a few notopodial spinigers in all parapodium. Numerous notopodial hooked blade is attached back by a distal terminal knob. This species was collected from Hurghada 2010, within algal bottom.

Remarks: This species is morphologically similar to the specimens collected by Day (1967) from Cape. This is new record for Egyptian waters.

Distribution: Endemic species for South Africa (Day, 1967).

\section{Platynereis nadiae Abbiati \& Castelli, 1992 (Fig. 6 A-E)}

Vieitez et al., 2004:328 fig. 119 a-n; Abbiati and Castelli, 1992:151-152, figs.1-5.

Notes: Two specimens collected from Hurghada (2010). Length 6-7mm, up to 16 segments. Description agrees with Vieitez's et al. (2004) samples. Prostomium, greater in length than width, with 4 eyes, 2 antennae and 2 massive palps. Four pairs of short annulated tentacular cirri. Paragnaths pectinate bars absent in the G.I $=0$, G.11=0, GIII= 3 short bars, G.IV= 2 rows of 3-4 pectinate bars, G.V=0 areas; G.VI = a single pectinate bar, VII-VIII = 5 pectinate bars arranged in a single row. Notopodium, and neuropodium with falcigers and spinigers chaetae. It collected from Hurghada 2010, within algal cover. 
Type locality: Mediterranean Sea (Italian coast).

Remarks: This species was recorded for the first time for Egyptian waters, and is considered new for Red Sea, so it may be considered an anti Lessepsian species.

Distribution: Mediterranean Sea; Tyrrhenian Sea (Island of Capraia); Alboran Sea (Chafarinas Islands; northern coast of Africa) (Vieitez et al., 2004).
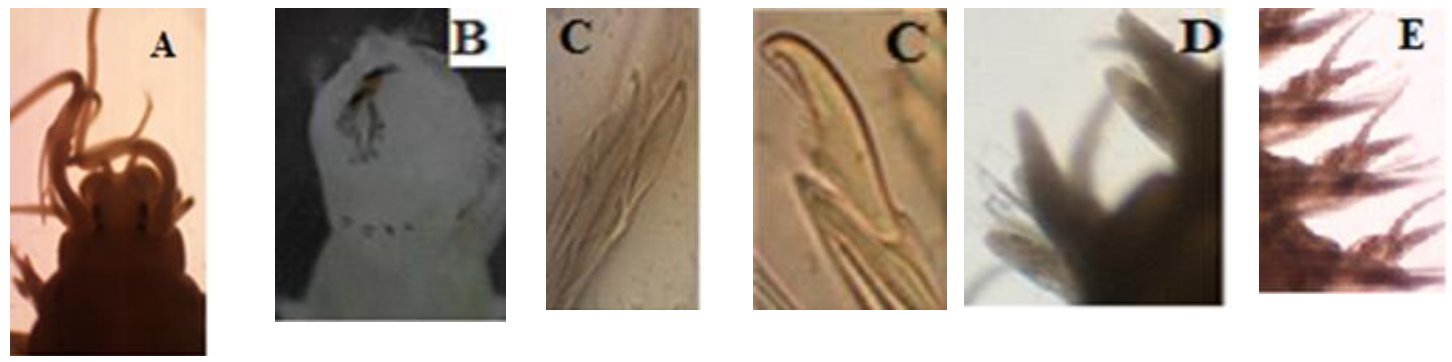

Fig. (2) Platynereis dumerilii, (A) dorsal view, (B) ventral view, (C) Neuropodial falciger, (D) Parapodium anterior (E) Posterior parapodia.
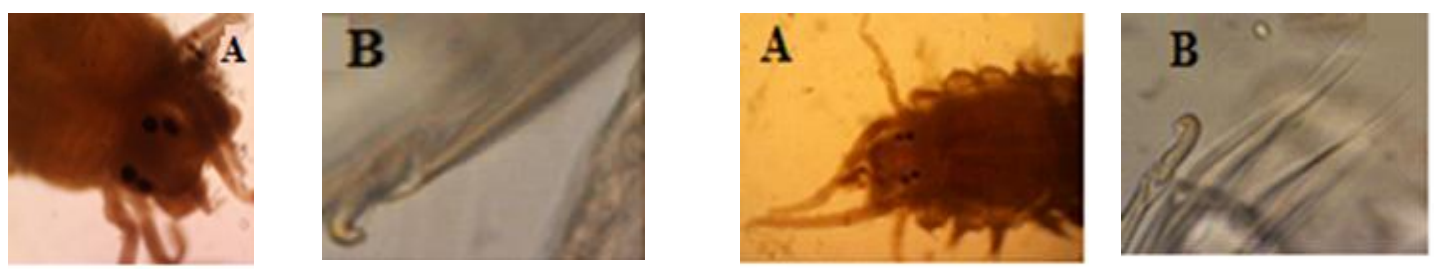

Fig. (3) Platyeies austalis, (A) Dorsal view, (B) Neuropodial falcigers; Fig.(4) Platynereis insolita, (A) Dorsal view (B) Chaetae.
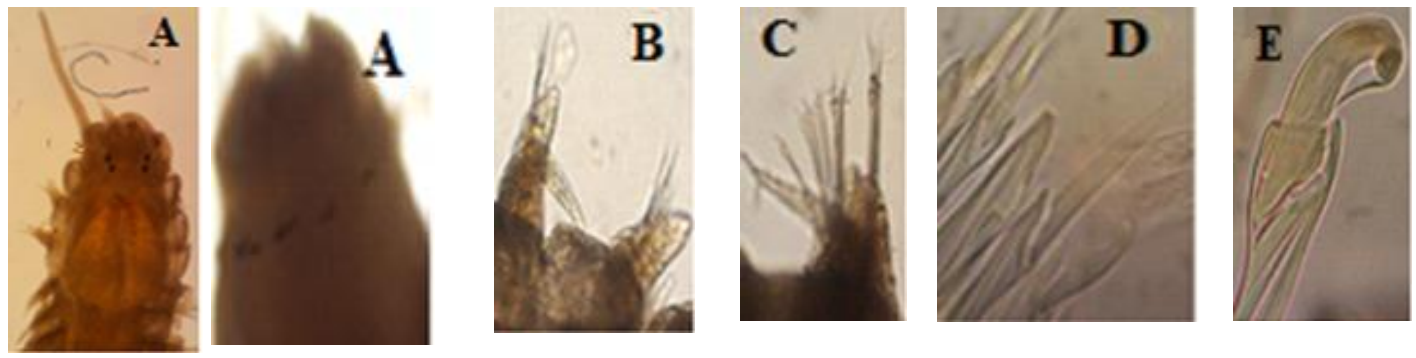

Fig. (5) Platynereis calodonta, (A) anterior and ventral view, (B) Parapodia anterior (C) Parapodia middle (D) Notopodium homogomph facigers and spinigers, (E) Neuropodial falcigers. 

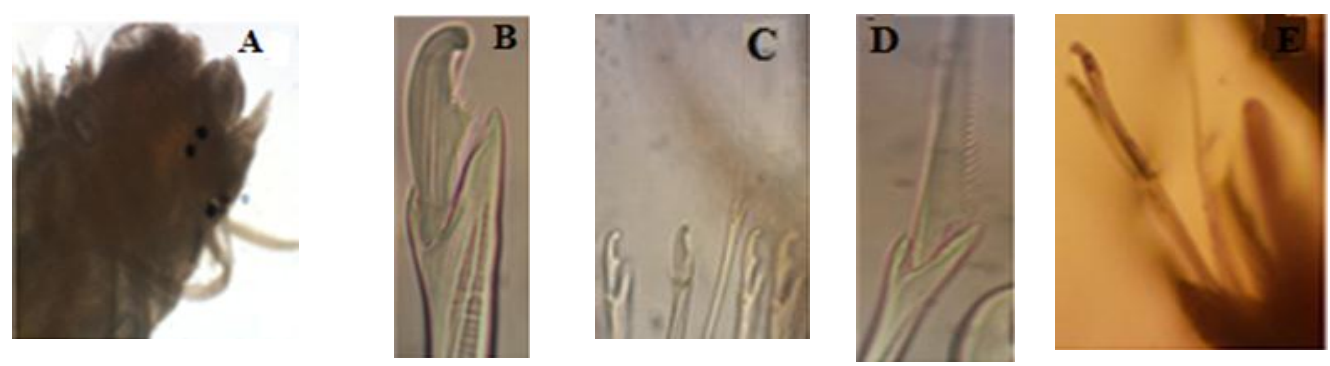

Fig. (6) Platynereis nadiae, (A) dorsal view (B) Notopodium, facigers, (C) Notopodium, falcigers \& spinigers, (D) Spinigers chaetae (E) Falcigers, mid body.

\section{Genus Neanthes Kinberg, 1865.}

\section{Neanthes kerguelensis (McIntosh, 1885) (Fig. 7 A-E)}

Vieitez et.al., 2004: 362 fig.133 a-h, Darbayshir, 2014: 89 fig. 4 a-e; Bakken and Wilson, 2005: 528.

Notes: Six specimens. Body length approximately 20-25 mm with 40-50 segments, color pale cream in alcohol, dark brown shading remaining over anterior chaetiger. Pharynx with conical paragnaths, variable in size. Paragnaths G. I= one cone, G.II= a crescentic patch (1-8), G.III= a small patch (1-9), G.IV= a crescentic patch (6-15), G.V=0, G.VI= one cone, G.VII-G.VIII= a row of approximately 5 cones. (Fig. 7 A, B). Parapodia biramous from chaetiger 3, subbiramous on 1-2. glands present (Fig. 7 C). Notochaetae with homogomph spinigers only. Neuropodia with homogomph spinigers and heterorogomph falcigers chaetae in both superior and inferior from number 3. Falcigers blades, on their ends have distinct knob (Fig. 7 D). No heterogomph spinigers present.

This species was collected from Marina (Western Mediterranean coast of Egypt, 2017), within fouling collection. It is considered new record for Egyptian waters.

Type locality: Western Australia.

Remarks: The features of the specimens agree with Vieitez's et. al. (2004) samples. Differs from Hartman's samples (1964) and Darbayshir's samples (2014) both founding falcigers blades without distinct knob at their tips, while the present specimens with distinct knob agrees with Vieitez et. al. (2004).

Distribution: Atlantic- Mediterranean (Vieitez et. al. 2004).

\section{Neanthes willeyi (Day, 1934) (Fig. 8 A-E)}

Nereis (Neanthes) willeyi Day, 1967: 320, fig 14.8. l-p.

Notes: Three specimens collected from Suez Canal 2015, in fouling samples. Body long, up to $35 \mathrm{~mm}$ with up to 54 segments, reddish in color. Paragnaths $\mathrm{G}$. I= a single point, $\mathrm{G} . \mathrm{II}=$ an opaque double row, G.III= an oval patch of a crescent group, G.IV= a wedge- 
shaped group, G.V=1, G.VI= a rosette of 7-8 points, G.VII-G.VIII= 3-4 irregular rows of numerous points (Fig. 8 A-B). It is characterized by long dorsal cirri on posterior parapodium. There are no notopodial falcigers. Posterior parapodium with neuropodial falcigers having blades with distinct knob attached to their tips (Fig. $8 \mathrm{C}$ ). This species was collected from Suez Canal 2015.

Type locality: Table Bay, South Africa

Remarks: The present specimens differ in group number G.VI from Day's samples (1967) where only 6 paragnaths were reported by the last author, also from Day's sample (1934) where the author found 4-8 paragnaths in rosette shape. This species is similar to $N$. succinea in its characters and number of paragnaths, but is easily distinguishable by the length of its dorsal cirri.

Distribution: Suez Canal; Persian Gulf; South Africa; Australia; New Zealand; Red Sea (Day, 1967; Wehe and Fiege, 2002) and Mediterranean sea.
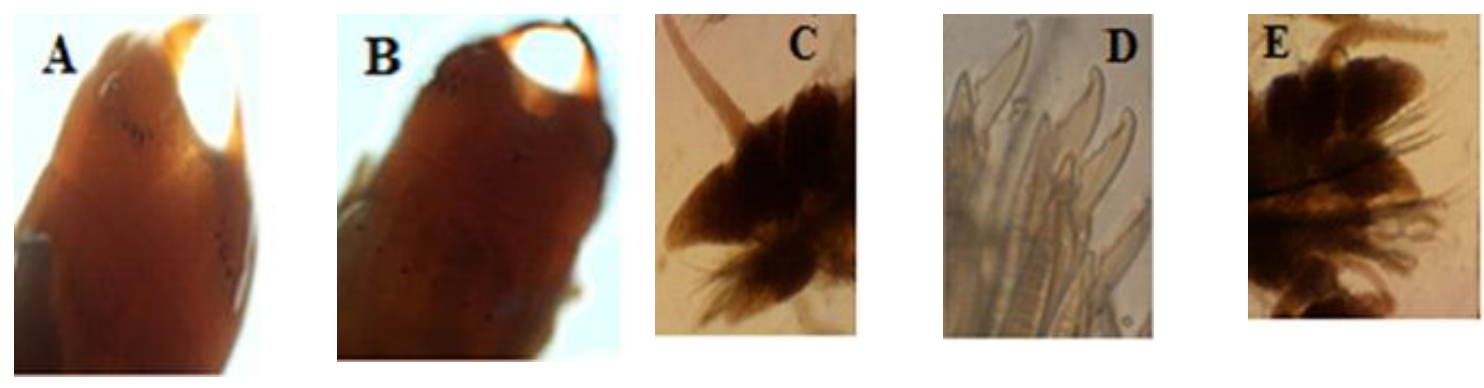

Fig. (7) Neanthes kerguelensis, (A) Dorsal view (B) Ventral view, (C) Anterior parapodia, (D) Falcigers chaetae, (E) Parapodia mid body.
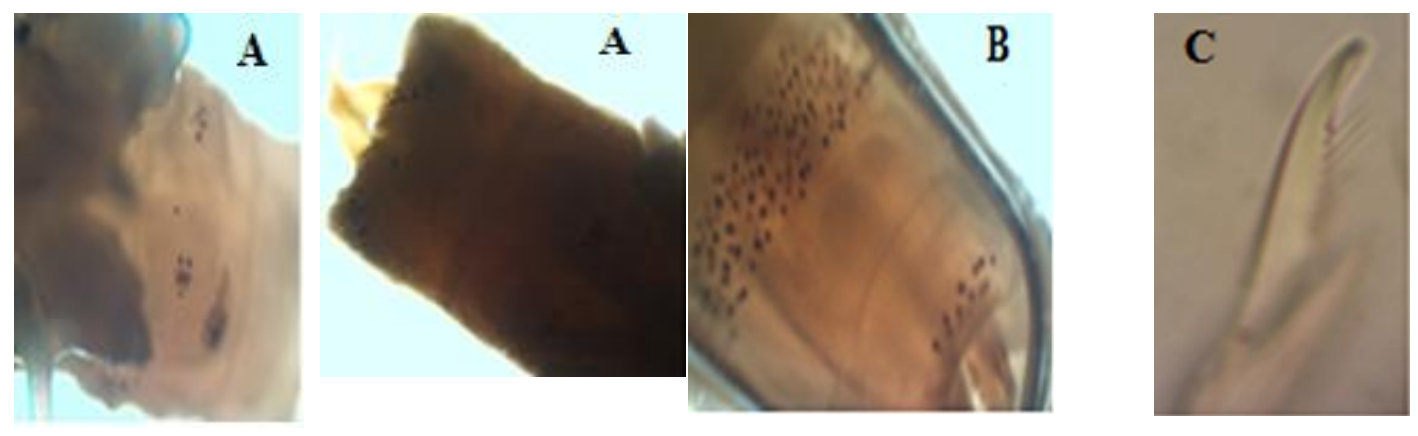

Fig. (8) Neanthes willeyi, (A) Dorsal view of pharynx, (B) Ventral view of pharynx, (C) Falcigers chaetae.

\section{Genus Alitta Kinberg, 1865}

\section{Alitta succinea (Leuckart, 1847) (Fig.9 A-E)}

Villalobos-GuerreroLuis and Carrera-Parra, 2015: 170 
Nereis succinea Vieitez et.al., 2004: 359 fig. 132 a-j; Dean, 2001:51fig 30-33

Nereis (Neanthes) succinea Day, 1967:321 figs 14.9. a-e; Dean, 1996: 73.

Notes: Four specimens were collected from Alexandria coast. Body up to $75 \mathrm{~mm}$ long, with up to 120 segments. Paragnaths grouped arranged as: G.I= 2-3 denticles in longitudinal line, G.II= patch of several oblique rows, G.III= rectangular cluster, G.V=13 denticles, G.VI= about 6 denticles in circle with one denticle inside, G.VII and VIII $=3$ rows (Fig.9 A-B). The top notopodial lobe is large and lamellate carrying the short dorsal cirrus in a notch at its end. No notopodial falcigers. Neuropodial falcigers have long straight blades without distinct tendons at their tips (Fig. 9 C). This species recorded from Alexandria by Abd Elnaby (2005), and Hamdy (2008).

Type locality: Alitta succinea was first described from the North Sea coast of Germany (Villalobos-GuerreroLuis and Carrera-Parra, 2015).

Remarks: The description disagrees with Vieitez et al. (2004), this author recorded 3 paragnaths in group I and a few paragnaths scattered, around 5 paragnaths in G.V. Also agrees with Day's samples (1967), but differs only in number G.V it has 6 paragnaths .

Distribution: Atlantic from North Sea, Tropical western Africa, Massachusetts to Gulf of Mexico, South to Uruguay, Pacific (California to Panama) (Vieitez et. al., 2004).
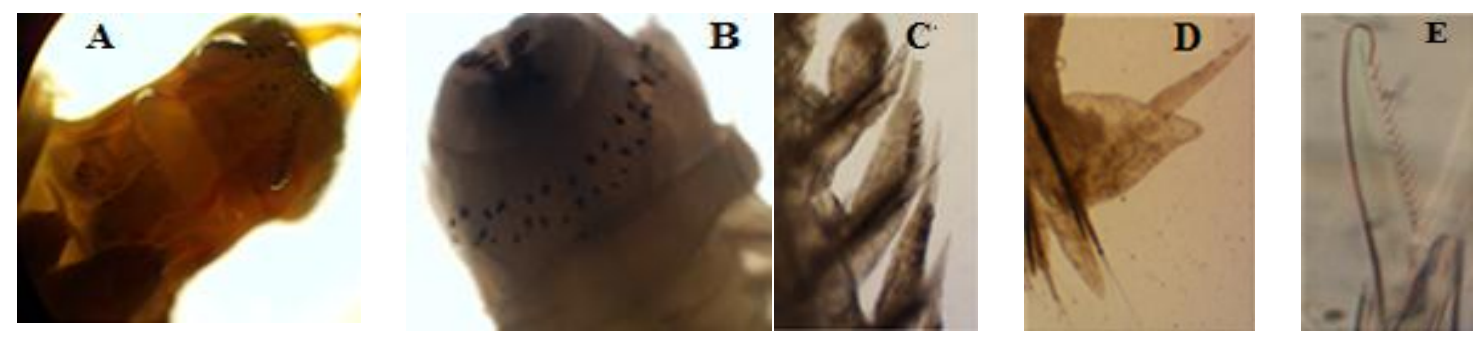

Fig. (9) Alitta succinea, (A) Dorsal (B) Ventral view, (C) Posterior parapodia, (D) Parapodia, (E) Heterogomph falcigers.

\section{Genus Nereis, Kinberg, 1865}

\section{Nereis jacksoni Kinberg, 1865 (Fig.10 A-D)}

Nereis (Nereis) jacksoni Day, 1967: 311, fig.14.5.n-t.

Notes: Uncompleted specimens 12, $20 \mathrm{~mm}$. Paragnaths G.I=0, G.II= double row, G.III $=$ oval patch of 4, G.IV= a wedge-shaped group, G.V=0, G.VI= a small close-set group of 4 paragnaths, G.VII-G.VIII= a single row of 7-8 paragnaths. All paragnaths pale and difficult to see, also because of their small size Parapodia anteriorly (Fig.10 A) with the notochaetae, homogomph spinigers (Fig.10 B) but in posterior notopodia, these are replaced by one to two stout falcigers (Fig.10 C) whose dark blades tip bears a large 
triangular denticle at a nearly right angle from its long axis, plus one or two much smaller denticles present below it. In neuropodia the heterogomph falcigers have slightly curved blades (Fig.10 D). This species collected from Gulf of Suez (Gabel El Zeit, 2018; Suez Canal 2015). This species is considered new for Suez Canal.

Type locality: Port Jackson, Australia.

Distribution: West Pacific; Red Sea; South Australia; New South Wales; Chatham Is; Madagascar; Cape and Mozambique and Mediterranean Sea (Day, 1967).

\section{Nereis persica Fauvel 1911 (Fig. 11 A-F)}

Ben-Eliahu, 1991: 322.

Nereis zonata persica Amoureux et. al., 1978: 83.

Notes: Length $10 \mathrm{~mm}$. with 60 segments. Paragnaths groups as in (Fig. 11 A-B-C-D). Posterior notochaetae include one to two dark homogomph falcigers, their blades with two to three blunt teeth. Neuropodial falcigers have curved blades with a slight tendon at the tip (Fig. 11 E-F). This species collected from Suez Canal and Gulf of Suez.

Type locality: Bouchir ( Bahrain, Arabian Gulf).

Suez Canal and Gulf of Suez.

Distibution: Eastern Mediterranean, Egypt (Port Said), Coast of Sinai Peninsula; Suez Canal- El Qantara; Red Sea- Gulf of Suez (Port Tawfiq); Persian Gulf; Indian Ocean; Pacific Ocean (Ben-Eliahu, 1991).
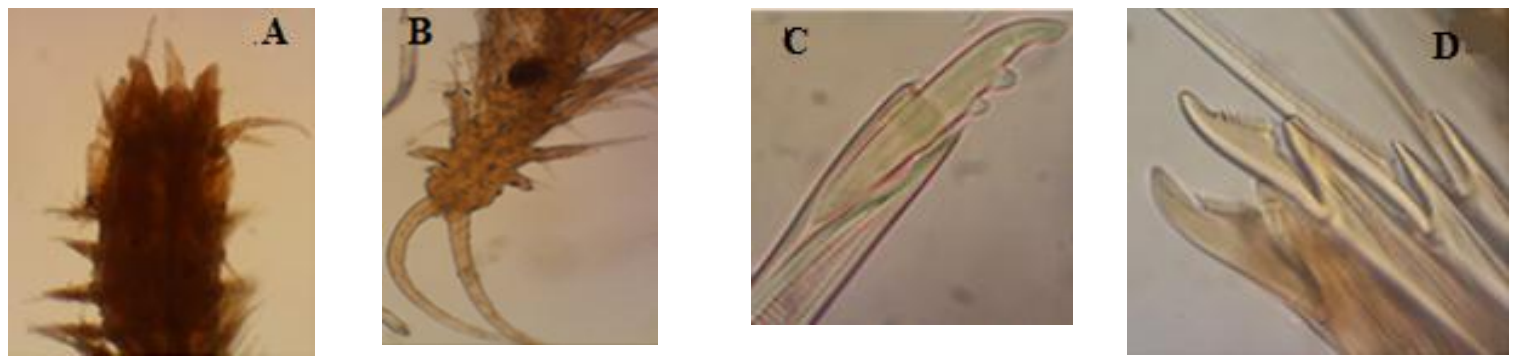

Fig. (10) Nereis jacksoni, (A) Anterior (B) Posterior part (C) Notopodial falcigers chaetae, (D) Heterogomph falcigers and spiniger. 

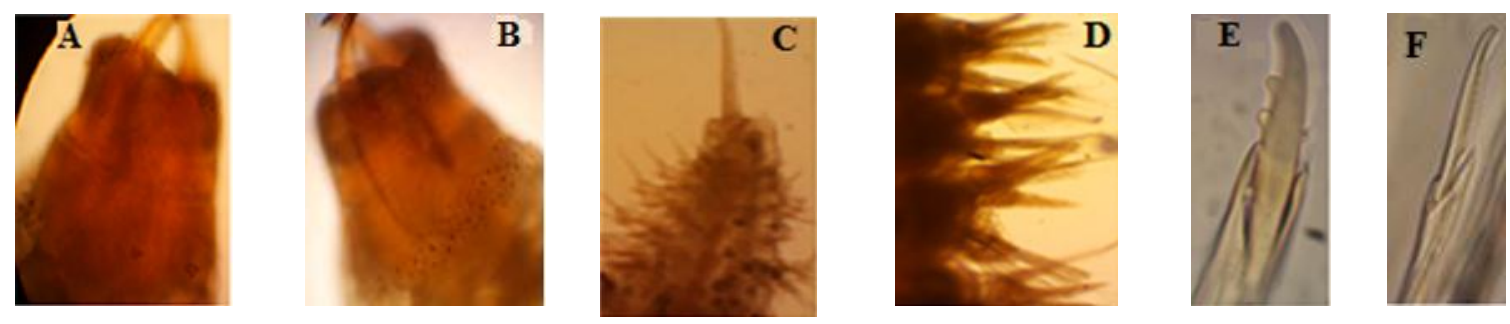

Fig.(11) Nereis persica, (A) Dorsal, (B) Ventral view, (C) Posterior part of body, (D) Parapodia, (E) Notopodial falcigers, (F) Heterogomph falcigers.

Genus: Ceratonereis Kinberg 1865.

\section{Ceratonereis mirabilis Kinberg, 1865 (Fig.12 A-B)}

Day, 1967: 324, fig. 14.14 a-g; Perkins, 1980:4 figs. 1-4; Çinar, 2009: 2292.

Notes: Three specimens were collected from El Dabaa, 2017, with coarse sand, body length up to $25 \mathrm{~mm}$, with up to 35 segments (Fig.12 A, B). It is considered new for Egyptian Mediterranean coast.

Type locality: Brazil

Remarks: Amoureux et al. (1978) reported this species from Aqaba Gulf; therefore it is considered as alien species.

Distribution: Suez Canal, Red Sea, W. Atlantic, Mediterranean Sea, Aqaba Gulf, Cyprus, Turkish coast, Brazil, Gulf of Mexico, Indo-West-Pacific to Japan (Çinar, 2009).

\section{Ceratonereis (Composetia) hircinicola (Eisig, 1870) (Fig.13 A-B)}

Vieitez et.al., 2004: 362 fig 121 a-j.

Notes: Five specimens, 25-30 mm long, 80-95 segments. Dirty brown head and anterior segments. Quick palps; quick tentacular cirri. Paragnaths G.I=0, G.II= 2 oblique lines, G.III= about 15 square area, G.IV= about 30 in a triangular group , G.VII-G.VIII= without paragnaths. All paragnaths are thin and conical (Fig.13 A). No notopodial falcigers; spinigers with short blades of posterior notopodia. Neuropodial Heterogomph falcigers with straight blades (Fig.13 B). This species collected from Suez Gulf 2018, Also collected 2013 from Eastern coast of Egypt (Damiatte, muddy sand 05m, El Burullus $350 \mathrm{~m}$ muddy bottom , Rasheed, 50m muddy bottom, with fine sand though the strategy of NIOF Institute, El yarmok trip, using Van Veen grab $\left(1 / 4 \mathrm{~m}^{2}\right)$, also it collected from Port Said within fouling. This species new recorded for Eastern Mediterranean coast of Egypt.

Type locality: Madagascar. 
Remarks: The Mediterranean specimens differ from Suez Gulf's specimens: in the number of paragnaths in G. II, G.III, G.IV, all are less in number.

Distribution: Mediterranean; Madagascar; Red Sea (Vieitez et.al., 2004).
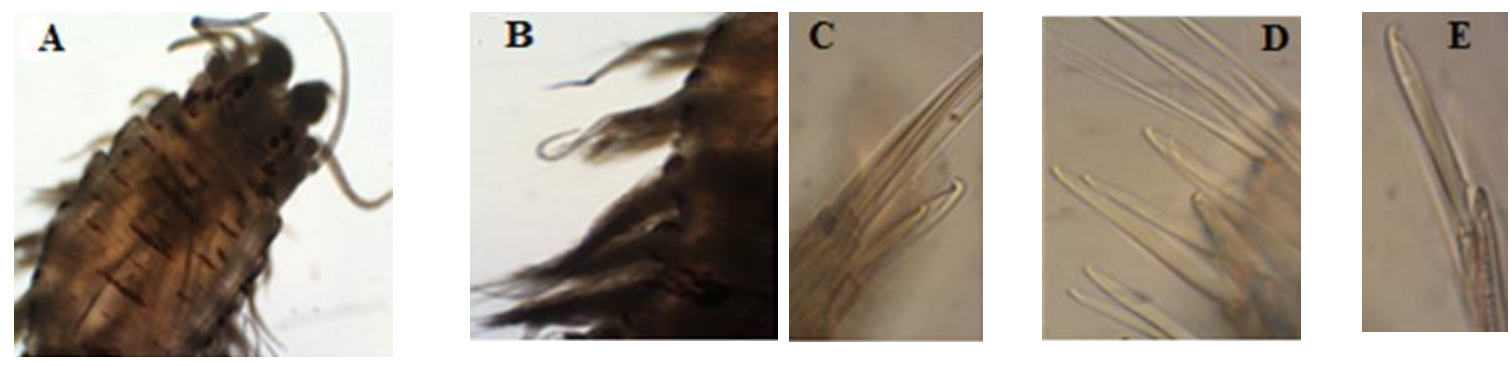

Fig. (12) Ceratonereis mirabilis, (A) Anterior part, (B) Parapodia; (C) Homogomph falcigers; (D, E) Heterogomph falcigers
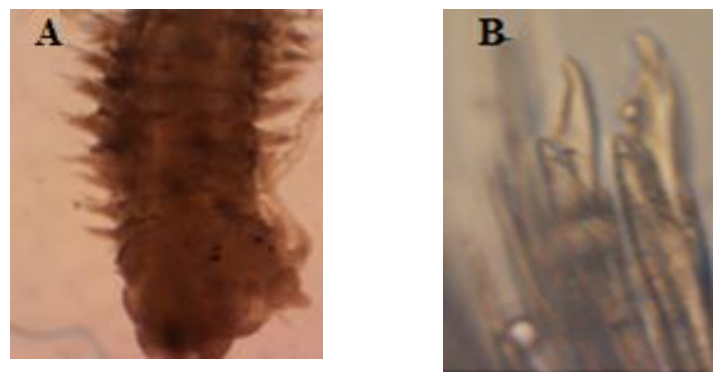

Fig. (13) Ceratonereis (Composetia) hircinicola, (A) Anterior part, (B) Falcigers chaetae.

\section{Genus Leonnates Kinberg, 1865}

\section{Leonnates decipiens Fauvel, 1929 (Fig.14 A-E)}

Hutchings and Reid, 1991:52; Day; 1967:330, fig. 14.11.n-s; Ben-Eliahu, 1991:

322; Qiu and Qian, 2000: 1123. Bonyadi-Naeini, et. al., 2017:49

Leonnates decipiens var. manilensis Pillai, 1965.

Notes: Six specimens. Long body up to $2 \mathrm{~cm}$ with around 70-90 segments, brown bars on anterior segments, robust palps and as long as the antennae. Color in alcohol creambrown with prominent glands visible in dorsal ligules and at the bases of the dorsal cirri (Fig.14 A, B). Notosetaechaetae homogomph spingers; neurosetaechaetae with homogomph spingers and heterogomph falcigers (Fig.14 C). From setiger 13, subacicular neuropodia with falcigers and blunt truncated tip and teeth below (Fig.14 D). This species collected from Abu-Qir (Alexandria), Port Said fouling collection, Suez Canal 2015. First reported for Suez Canal and Mediterranean by Ben-Eliahu (1972), Zenetos et. al. (2010) and Çinar (2013), the authors are considered this species as 
lessepsian migrant species, because this species is Indo-Pacific, entered the Mediterranean through Suez Canal. Then it reported from Turkey by Çinar (2009), who confirmed this result.

Type locality: Gulf of Manaar (India).

Distribution: Senegal, Congo, Suez Canal. Indian Ocean: Gulf of Oman; Krusadai and Pamban islands (Gulf of Mannar); Red Sea; Tropical Indo-Pacific and Mediterranean Sea (Ben-Eliahu, 1972 and Day, 1967).

\section{Leonnates indicus Kinberg, 1865.}

Leonnates indicus Bonyadi-Naeini et al., 2017:49, Qiu and Qian, 2000: 1113.

Leonnates jousseaumi Day, 1967: 330-331.

Notes: Tow specimens were collected from Suez Gulf. Body up to $60 \mathrm{~mm}$ long, 95 setigers. Colour, cream yellow to rust brown. (Fig.15 A-B). Paragnaths arranged as G.I = 0, G.11 = up to 7, G. III = 3-8, G.IV = 7-20 paragnaths or papillae. G.V = 0, G.VI=6-12, G.VII-G.VIII $=20-42$ in 2-3 irregular rows. Notopodia with homogomph spinigers along body (Fig.15 D), and few homogomph falcigers in far posterior setigers (Fig.15 C). Neuropodia with spinigers and falcigers. Falcigers with serrated blades, distally curved with a pointed terminal tooth (Fig.15 E). This species collected from Suez Gulf in 2017.

Type locality: Gulf of Tadjourah (Djibouti, Gulf of Aden).

Distribution: Australia (Northern Australia); Red Sea; Malay Peninsula; Madagascar; Indonesia; India; Gulf of Manna Pambam and Pakistan.
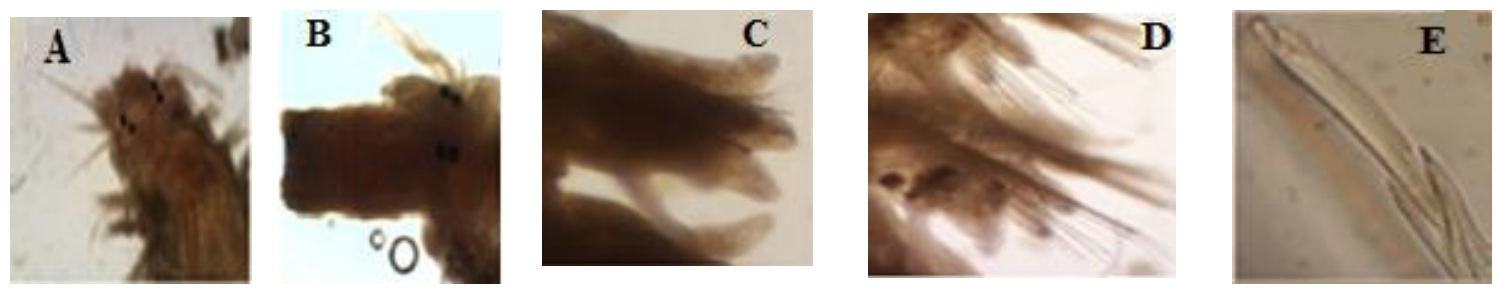

Fig. (14) Leonnates decipiens, Anterior part, (B) Dorsal view of proboscis, (C) Anterior parapodia (D) Falcigers and spinigers, (E) Posterior falcigers. 

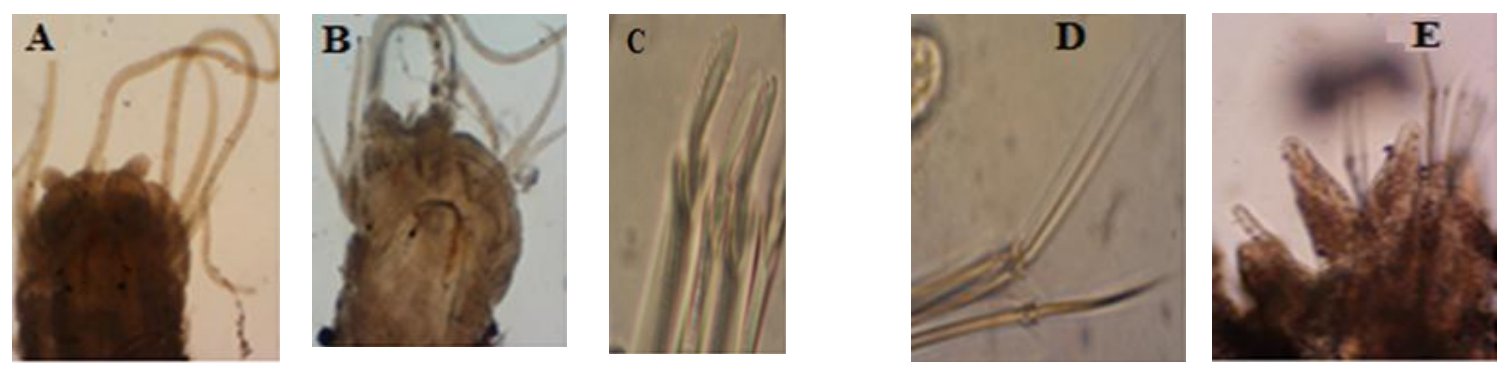

Fig. (15) Leonnates indicus,(A)Anterior view, (B) Ventral view, (C) Homogomph falcigers, (D) Homogomph spinigers, (E) Parapodia.

\section{Genus Perinereis Kinberg, 1865}

\section{Perinereis cultrifera (Grube, 1840) (Fig.16 A-B)}

Perinereis cultrifera Day, 1967: 337 fig. 14.13 o-q; Hartmann-Schröder,1996; Hind et al., 2016:162.

Notes: Color yellowish greenish, $2.5 \mathrm{~mm}$ long with up to 30 setigers. Paragnaths (Fig.16 A). Falcigers with short blades (Fig.16 B). This species was collected from Western coast of Alexandria (Marina, 2017). Previously reported by Abd Elnaby (2005), Hamdy (2008).

Type locality: E. Mediterranean Sea.

Distribution: Atlantic; Red Sea; Suez Canal; Aqaba Gulf; Persian Gulf; Pacific (Day, 1967) and Mediterranean Sea.

\section{Perinereis heterodonta (Gravier 1899) (Fig. 17 A-E)}

Perinereis heterodonta Shetav et. al., 2011: 54-57, figs. 2B, 5A-F,

Notes: One specimen, $22 \mathrm{~m}$ long, 70 segments. Pigmentation absent, Jaws dark brownish. Paragnaths: G.I= 2; G.II= 6-9, G.III = 9-12 (distinct lateral group present), G.IV=18 cones, bars absent; G.V=0; G.VI= 3-4 cons; G.VII-G.VIII= 18-35 large cones in 3 irregular rows (Fig.17 A-B). Ventral fascicle has chaetae heterogomph falcigers, with blades in different length and strong serration (Fig.17 C-F). This species collected from Suez Canal 2015. It recorded before by Bellal (2001) from Suez Bay, also from Egyptian Mediterranean coast (Alexandria) by Abd Elnaby (2005).

Type locality: Red Sea.

Distribution: Indian Ocean: Gulf of Aden (Djibouti): Gulf of Oman (Iran); Persian Gulf Suez Canal; Red Sea; Arabian Gulf; Suez Bay (Wilson and Glasby, 1993). 

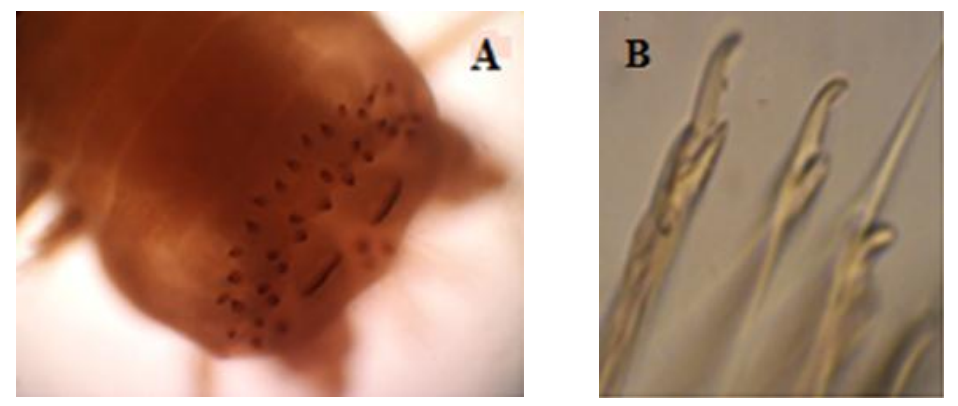

Fig. (16) Perinereis cultrifera, (A) Proboscis, (B) Chaetae.
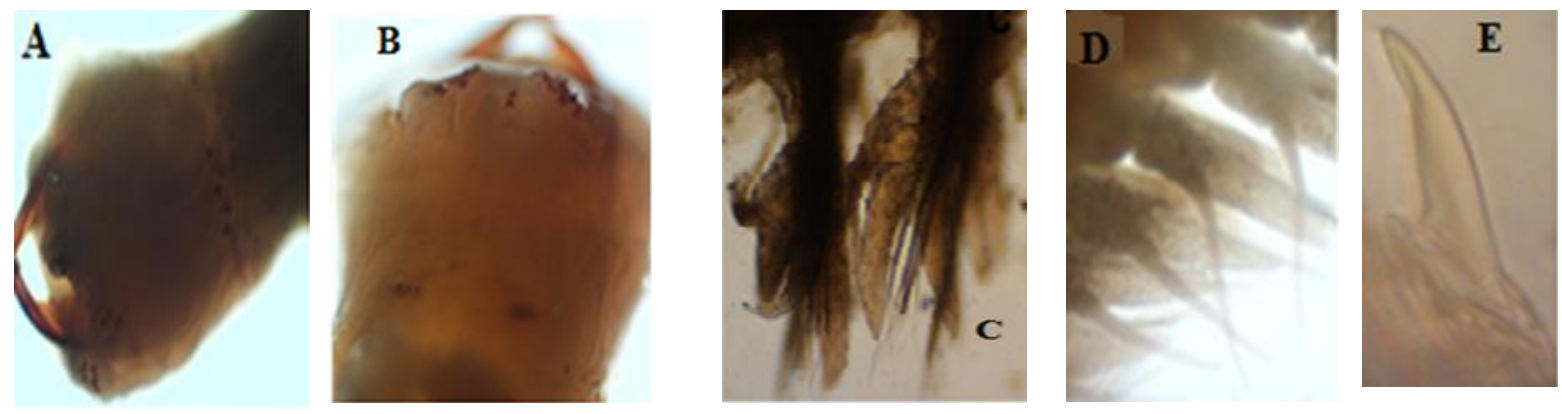

Fig. (17) Pereneries heterodonta, (A) Dorsal view, (B) Ventral view, (D) Parapodia anterior, (C) Parapodia posterior, (E) Falcigers chaetae.

\section{Genus Pseudonereis Kinberg, 1865.}

\section{Pseudonereis variegata (Grube, 1857) (Fig. 18 A-E)}

Fauvel, 1953: 215, fig. 110 a-c; Hartmann-Schröder, 1962: 434-435; Bakken, 2007: 169, fig 14,15 .

Notes: Two specimens, about $150 \mathrm{~mm}$ long with up to 100 segments, dark green. In color. Paragnaths arranged as follows: G.I= a single conical paragnath; G.II= 3 rows of 12-34; $\mathrm{G} . \mathrm{III}=4$ rows of up to 35 points; $\mathrm{G} . \mathrm{IV}=4$ rows of up $40 ; \mathrm{G} . \mathrm{V}=$ a single large paragnath; G.VI= one shield-shaped bar of paragnath on each side; G.VII- G.VIII= two irregular rows of up to 15 paragnaths (Fig. 18A-B). Paragnaths of G. II, G.III and G.IV arranged in a comb-like rows. Parapodia with longer dorsal cirrus. Posterior dorsal cirri larger, flattend and lamellate carrying the small dorsal cirrus at its truncate end. Notochaetae: homogomph spinigers throughout. Neuropodial falcigers with short, faintly hooked blades. This species was recorded from Suez Canal 2015, it is new record for Egyptian waters.

Type locality: Chile and Peru

Distribution: South West Africa, Mozambique, and the southAmerica 


\section{8- Pseudonereis anomala Gravier, 1899 (Fig. 19A-E)}

Pseudonereis anomala Alessandro et. al., 2015:1 fig. 2 a-f; Glasby et. al., 2013:259, fig.7a, b.

Notes: Fifty two specimens were collected from Port Said, Alexandria and Suez Canal. Body with up to 30 chaetigers, total length up to $14 \mathrm{~mm}$. Paragnaths groups (Fig. 19A-B). Notochaetae include heterogomph falcigers and homogomph spinigers from first parapodium (Fig. 19 C, E). This species collected from Suez Canal 2015; Port Said 2015, 2016; Alexandria 2017 and recorded before from many shores of Alexandria (Mediterranean coast of Egypt) (Dorgham et. al., 2013, Abd Elnaby, 2005).

Type locality: Djibouti, Gulf of Aden.

Remarks: Pseudonereis anomala is considered to be an alien species (Çinar and Altun, 2007); Dorgham et. al., 2013, Abd Elnaby, 2005).

Distribution: It has a wide distribution, the Arabian Sea to the Indo-west Pacific, Australia. (Alessandro et. al., 2015 and Cinar, 2005).
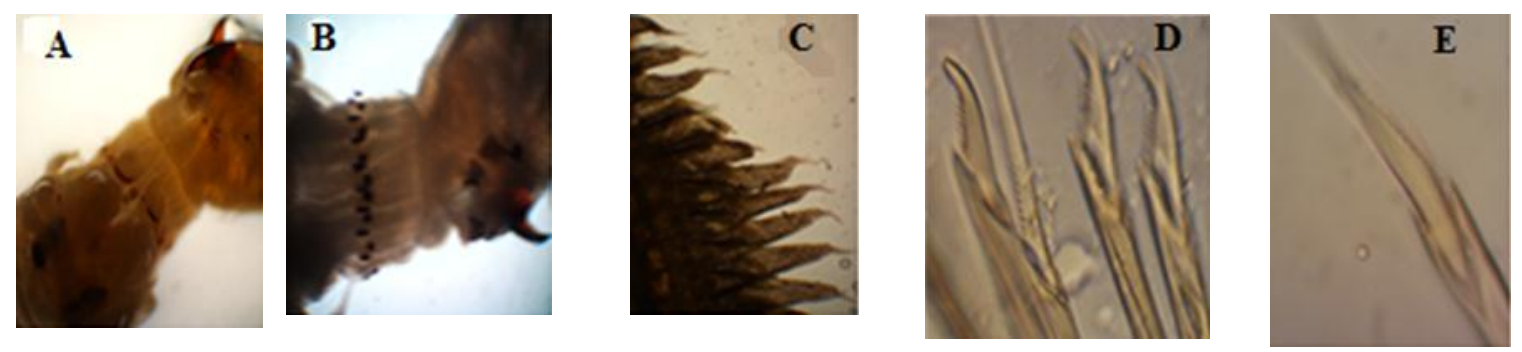

Fig.(18) Pseudonereis variegata,(A) Dorsal view, (B) Ventral view, (C) Parapodia, (D) Neuropodial heterogomph falcigers, (E) Notochaetae homogomph spinigers
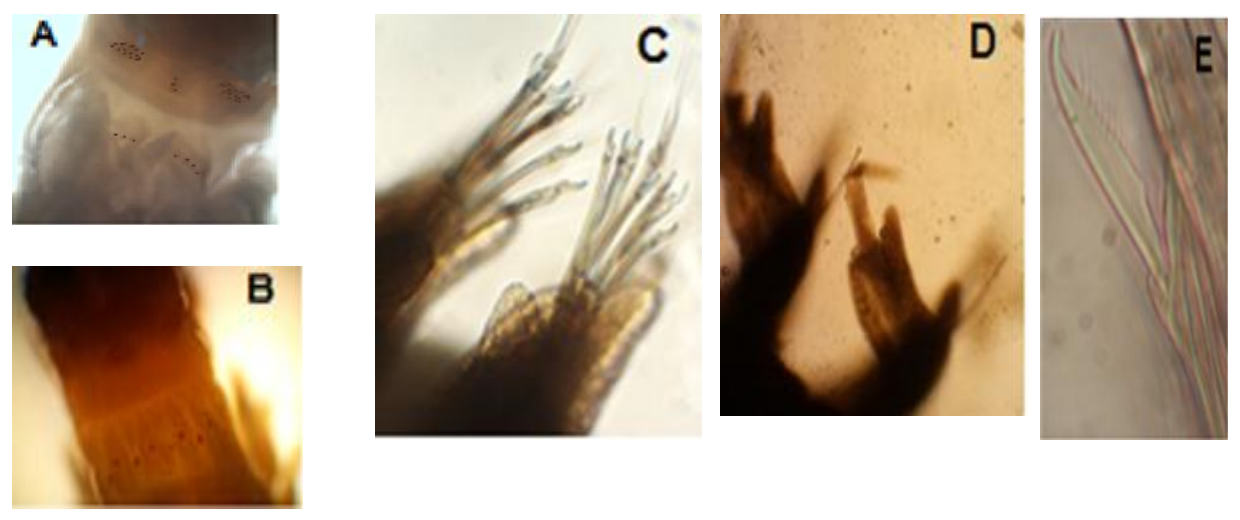

Fig.(19) Pseudonereis anomala, (A) Dorsal view, (B) Ventral view, (C) Parapodia anterior, (D) Parapodia posterior, (E) Heterogomph falcigers. 


\section{DISCUSSION}

The current work recorded for the Egyptian water, 18 Nereididae species belonging to 8 genera. Three species were recorded from the Suez Gulf, 10 species in the Suez Canal, 14 species in the Red Sea, and 10 species were recorded in the Mediterranean Sea.

Of these 9 were confirmed alien species: Ceratonereies mirabilis, Leonnates decipiens, Neanthes willeyi, Nereis jacksoni, Nereies persica, Platyneries australis, Pseudonereis anomala, Alitta succinea and Platynereis dumerilii

(Zenetos, et.al., 2010; Çinar, 2013). Apparently A. succinea, of Atlantic origin arrived by ships to South Africa (Med et. al., 2011), while P. dumerilii arrived by ships to Brazil (Neves and Rocha, 2008). Six species are new recorded species. They are: Platynereis calodonta, Platynereis nadiae, Neanthes kerguelensis, Ceratonereis (Composetia) hircinicola, Pseudonereis variegate and Leonnates indicus.

Pseudonereis variegata and Nereis jacksoni are considered new to both the Suez Canal and Suez Gulf. Even Ceratonereis (Composetia) hircinicola was found within sand samples collected from Suez Gulf and also present in the samples collected from the eastern Egyptian Mediterranean coast (Damietta, Rashid and Port Said). So it is considered exotic organism which came to the Mediterranean by either ships or ballast water. It is therefore, considered new recorded species for the Mediterranean Sea. Also Ceratonereis mirabilis was Indo-Pacific in its origin, and reported as lessepsian species came to Mediterranean through Suez Canal (Zenetos et al., 2010), It collected from El Dabaa (Egypt's west coast) in 2017.

Leonnates decipiens, is accounted for in the Suez Canal and in the Mediterranean coast of Egypt (Abo-Qir station) through this exploration, so it is viewed as alien species, this is concurrence with the, discoveries of Çinar $(2009,2013)$. Pseudonereis variegata (Grube, 1857) was accounted for from South Africa, and in the current investigation it is recorded from the Suez Canal, which implies a constant spreading of alien species. Leonnates indicus likewise announced as alien species by Çinar (2013) and Zenetos et al. (2010), It is Indo-pacific species entered the Mediterranean through Suez Canal, it is new record for Egyptian waters. Williamson and Fitter (1996) detailed that in the receiving area $10 \%$ of the alien species could be established and $1 \%$ of them would become invasive.

Additionally Çinar (2013), referenced that this rule can't be applied all over the place, Zenetos et. al., (2010) indicated that Mediterranean counted 45\% of the complete number of alien established species, $18 \%$ of them have invasive characters, for example, Perineries cultrifera and Pseudonereis anomala, they have been established in the Mediterranean. This study is another endeavor to report specific sorts of Nereididea species in the Egyptian waters recorded for the first time, which improves our insight into this family, and increase our knowledge to increase biodiversity of polychaetes in Egypt. 
Probably many of the reported species were always present in Egyptian waters and their absence is due only to the few existing works and scarce publication of polychaetes in Egypt, so this exploration is viewed as an expansion to this subject.

\section{REFERENCES}

Abbiati, M. and Castelli, A. (1992). Platynereis nadiae sp. n. (Polychaeta: Nereididae) from Italian coasts. Zool. Scrip., 21(2): 151-155.http://dx.doi.org/10.1111/j.14636409.1992.tb00317.x

Abd Elnaby, F. A. (2005) . Systematic and environmental studies on Polychaetes from Alexandria marine water, Ph. D. thesis, Suez Canal Univ., 330 pp.

Abd Elnaby, F. A. (2009). New records of Polychaetes from the South Part of Suez Canal, Egypt. Worl. J. Fish. and Mar. Sci., 1 (1): 7-19.

Alessandro, M. D.; Castriota, L.; Consoli1, P.; Romeo1, T. and Andaloro, F. (2015). Pseudonereis anomala (Polychaeta, Nereididae) expands its range westward: first Italian record in Augusta and Siracusa harbours, Mar. Biod. DOI 10.1007/s12526-015-0334-8.

Amoureux, L.; Rullier, F. and Fishelson, L. (1978). Syste'matique et 'ecologie d'ann'elides polych 'etes de la presqu'il du Sinai. Isr. J. Zool., 27 (1-2): 57-163.

Barbary, M. S. (1992). Surveillance and ecological studies on the polychaetes in Lake Timsah (Suez Canal,Egypt). Ph.D. Thesis. Zagazig University, 249pp.

Bakken, T. and Wilson, R. S. (2005) Phylogeny of nereidids (Polychaeta, Nereididae) with paragnaths. Zool. Scrip. 34: 507-547. doi: 10.1111/j.1463-6409.2005.00200.x.

Bakken, T. (2007). Revision of Pseudonereis (Polychaeta, Nereididae). Zool. J. Linn. Soc., 150:145-176. 16 figs.

BelLal, A. A. (2001). Ecological studies on the polychaetes in Suez Bay. Ph.D. Thesis, Faculty of Science Zagazig University, 295pp.

Ben Eliahu, M. N. (1972). A description of Hydroides steinitzi n. sp. (Polychaeta: Serpulidae) from the Suez Canal with remarks on the Serpulid fauna of the canal. Isr. J. Zool., 21: 77-81.

Ben-Eliahu, M. N. (1991). Nereididae of the Suez Canal Potential lessepsian migrants? Bull. Mar. Sci., 48: 318-329.

Bonyadi-Naeini, A.; Rasthgar-Pouyan, N.; Rasthgar-Pouyan, E.; Glasby,C.; Rahimian, H. (2017). Nereididae (Annelida: Phyllodocida) of the Persian Gulf and Gulf of Oman, including description of two new species and 11 new records. Zootaxa, 4244 (1): 091117. DOI: http://dx.doi.org/10.11646/zootaxa.4244.1.5 
Çınar, M.E. (2005). Polychaetes from the coast of northern Cyprus (eastern Mediterranean Sea), with two new records for the Mediterranean Sea. Cah. Biol. Mar., 46: 143-161.

Çinar, M. E. (2013). Alien polychaete species worldwide: current status and their impacts. J. Mar. Biol. Assoc. Unit. King., 93(5): 1257-1278.

Çinar, M. E. (2009). Alien polychaete species (Annelida: Polychaeta) on the southern coast of Turkey (Levantine Sea, eastern Mediterranean), with 13 new records for the Mediterranean Sea. J. Nat. Hist., 43(37-38): 2283-2328.

Çinar, M. E. and Altun, C.A. (2007). A preliminary study on population char-acteristics of the Lessepsian species, Pseudonereis anomala (Polychaeta: Nereididae), in Iskenderun Bay (Levantine Sea, eastern Mediter-ranean). Turk. J. Zool., 31: 403-410.

Darbayshire, T. (2014). Intertidal and nearshore Nereididae (Annelida) of the Falkland Islands, South weastern Atlantic, including a new species of Gymnonereis. Zookeys 427:5-108. doi: 10.3897/Zookeys.427.7296.

Day, J. H. (1934). On a collection of South African Polychaeta, with a catalogue of the species recorded from South Africa, Angola, Mosambique, and Madagascar. J. Linn. Soc. Lond., Zool., 39(263): 15-82., http://dx.doi.org/10.1111/j.1096-3642.1934.tb00259.x

Day, J. (1962). Polychaeta from several localities in the western Indian Ocean. Proceed. Zool. Soci. Lond., 39(4): 627-656.

Day, J. H. (1967). A monograph on the Polychaeta of Southern Africa. Brit. Mus. (Natural History). Lond., 1 and 2: 1-878., http://www.biodiversitylibrary.org/bibliography/8596.

Dean, H. K. (1996). Subtidal benthic polychaetes (Annelida) of the Gulf of Nicoya. Costa Rica. Rev. Biol. Trop. 44 (Suppl. 3): 69-80.

Dean, H.K. (2001). Some Nereididae (Annelida: Polychaeta) from the Pacific Coast of Costa Rica. Rev. Biol. 49 (2): 37-67.

Dorgham, M. M.; Hamdy, R.; Al-Rashidy, H. H. and Atta, M. M. (2013). First records of polychaetes new to Egyptian Mediterranean waters. Oceanologia, 55 (1): 235-267.

Esselink, P. and Zwarts, L. (1989). Seasonal trend in burrow depth and tidal variation in feeding activity in Nereis diversicolor. Mar. Ecol. Progr. Ser. 56: 243-254.

Fauvel, P. (191I). Annelides polychetes du golfe Persique recueillies par M. M. Bogoyawlewsky. Archiv. Zool. Exper. Generale, 5 (6): 353-439.

Fauvel, P. (1929). Polychètes nouvelles du Golfe de Manaar (Inde). Bull. Soc. Zool. de France. 54: 180-186., http://gallica.bnf.fr/ark:/12148/bpt6k5442558m/f241.

Fauchald, K. and Jumars, P. (1979). The diet of worms: A study of polychaete feeding guilds. Oceano. Mar. Biol. Ann. Rev. 17: 193-284. 
Fischer, A. and Dorresteijn, A. (2004). The polychaete Platynereis dumerilii (Annelida):a laboratory animal with spiralian cleavage, lifelong segment proliferation and a mixed benthic/pelagic life cycle. Bio Essays 26:314-325, Inc. DOI 10.1002/bies.10409.

Ganesan, M. and Monisha, N. (2017). Consumption of carrageenophyte Sarconema filiforme by Platynereis insolita (Polychaeta: Phyllodocida: Nereididae)-laboratory experiments and out planting. J Appl Phycol, 29:3029-3037. DOI 10.1007/s10811-017$1182-7$

Glasby, C. J.; Wei, N. V. and Gibb, K. S. (2013). Cryptic species of Nereididae (Annelida : Polychaeta) on Australian coral reefs. Invert. Syst., 27: 245-264. http://dx.doi.org/10.1071/IS12031

Hamdy, R. (2008). Ecological studies on benthic polychaetes along Alexandria coast, M. Sc. thesis, Alex. Univ., 214 pp.

Hartman, O. (1974). Polychaetous annelids of the Indian Ocean including an account of species collected by members of the International Indian Ocean Expeditions, 1963-'64 and a catalogue and bibliography of the species from India. J. mar. biol. Ass. India, 16(1): 191-252.

Hartmann-Schröder, G. (1985). Revision der Gattung Ceratonereis Kinberg (Nereididae, Polychaeta) (Mit besonderer Berücksichtigung der Arten mit enigeschnittenem Prostomium). Mitteilungen aus dem Hamburgischen zoologischen Museum und Institut, 82: 37-59.

Hartmann-Schroeder, G. (1996). Annelida, Borstenwuermer, Polychaeta.In: Dahl M, Peus F, editors. Tierwelt Deutschlands. 58. 2nd ed. Jena:Gustav Fischer.

Hilbig, B. (1997). Chapter 12. Family Nereididae Johnston, 1845. In J. A. Blake, B. Hilbig \& P. H. Scott (eds.) Taxonomic atlas of the benthic fauna of the Santa Maria Basin and Western Santa Barbara Channel, Volume 4, The Annelida Part 1. Santa Barbara Mus. Nat. Hist., Santa Barbara, pp. 291-316

Hind, G.; Ouided, M.; Tarek, D.; Patrick, S. (2016). First record of Perinereis macropus and Perinereis cultrifera (Annelida, Polychaeta) from rocky shores east Algeria, (SW Mediterranean sea). J. Entom. Zool. Stud. 4, (4): 160-166.

Hutchings, P. and Reid, A. (1991). The Nereididae (Polychaeta) from AustraliaLeonnates, Platynereis and Solomononereis. Record. Aust. Mus. 43:47-62.

Imajima, M. (1972). Review of the annelid worms of the family Nereidae of Japan, with descriptions of five new species or subspecies. Bull. Nat. Sci. Mus., Tokyo, 15(1): 37153.

Imajima, M. and Hartman, O. (1964). The polychaetous annelids of Japan. Occasional Papers of the Allan Hancock Foundation, 26 (1-2): 1-452. http://digitallibrary.usc.edu/cdm/ref/collection/p15799coll82/id/18946. 
Mead, A.; Carlton, J.T.; Griffiths, C.L. and Rius, M. (2011). Introduced and cryptogenic marine and estuarine species of South Africa. J. Nat. His., 45: 24632524.

Neves, C. S. and Rocha, R. S. (2008). Introduced and cryptogenic species and their managements in Paranagua Bay, Brazil. Brazil. Archiv. Biol. Technol., 51: $623-633$.

Perkins T. H. (1980). Review of species previously referred to Ceratonereis mirabilis and descriptions of new species of Ceratonereis, Nephtys, Goniada (Polychaeta). Procced. Biol. Soc. Wash. 93(1): 1-49.

Pillai, T.G. (1965). Annelida Polychaeta from the Philippines and Indonesia. Ceylon J. Sci. (Biol. Sci.), 5(2): 110-177., http://dl.nsf.ac.lk/handle/1/7733.

Rosenfeldt, P. (1989). Die polychaeta der Rotmeer- Expedittionen Meseda I (1977) mit (Sonne) und Meseda II (1979) mit F ( Valdivia). Senckenbergiana, 69 (1/3): 213-242.

Selim, S. A. (2009). Polychaete fauna of the northern part of the Suez Canal (PortSaid-Toussoum). Egypt. J. Aqu. Res., 35 (1): 69-88.

Shetav, Y.; Rahimian, H.; Nabavi, S.; Mohammad, B.; Glasby, C. (2011). Nereididae (Annelida: Polychaeta) from intertidal habitats in the Gulf of Oman, Iran. Zootaxa. 3013: 48-64., available online at http://mapress.com/j/zt/article/view/11850.

Qiu, J.W. and Qian, P.Y. (2000) Revision of the genus Leonnates Kinberg, 1866 (Polychaeta: Nereididae), with descriptions and comments on other species described in Leonnates. Proceed. Biol. Soc. Wash., 113: 1111-1146.

Vieitez, J. M.; Alós, C.; Parapar, J.; Besteiro, C.; Moreira, J.; Nunez, J.; Laborda, J. and San Martin, G. (2004). Annelida Polychaeta I. Fauna Iberica. Ramos, M.A. et al (Eds.). Museo Nacio. Cienc. Nat., CSIC, Madrid, 25:1-530.

Villalobos-Guerrero, T. F. and Carrera-Parra, L. F. (2015). Redescription of Alitta succinea (Leuckart, 1847) and reinstatement of A. acutifolia (Ehlers, 1901) n. comb. based upon morphological and molecular data (Polychaeta: Nereididae). Zootaxa, 3919 (1):157-178. DOI: 10.11646/zootaxa.3919.1.7.

Wehe, T. and Fiege, D. (2002). Annotated checklist of the polychaete species of the seas surrounding the Arabian Peninsula: Red Sea, Gulf of Aden, Arabian Sea, Gulf of Oman, Arabian Gulf. Fau. Arab., 19 (7): 7-238.

Wilson, R. and Glasby, C. (1993). A revision of the Perinereis nuntia species group (Polychaeta: Nerididae). Record. Aust. Mus., 45(3):253-277. 
Williamson, M. and Fitter, A. (1996). The Varying Success of Invaders. Ecol., 77: 1661-1666. http://dx.doi.org/10.2307/2265769

Zenetos, A.; Gofas, S.; Verlaque, M.; Ç inar, M. E; Garc'ıa Raso, J. E.; Bianchi, C. N.; Morri, C.; Azzurro, E.; Bileceno glu, M.; Froglia, C.; Siokou, I.; Violanti, D.; Sfriso, A.; San Mart'ın, G.; Giangrande, A.; Katagan, T.; Ballesteros, E.; Ramos, A.; Mastrototaro, F.; Ocana, O.; Zingone, A.; Gambi, M. C and Streftaris, N. (2010). Alien species in the Mediterranean Sea. A contribution to the application of European Union's Marine Strategy Frame work Directive (MSFD). Part I. Spatial distribution. Med. Mar. Sci., 11 (2): 381-493. 